NASA Technical Memorandum 113177

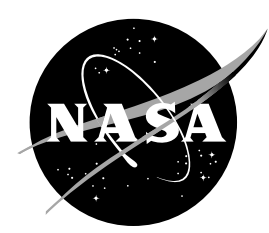

Improvement in Suppression of Pulsed Nd:YAG Laser Light With Iodine Absorption Cells for Filtered Rayleigh Scattering Measurements

Richard G. Seasholtz and Alvin E. Buggele

Lewis Research Center, Cleveland, Ohio 


\section{The NASA STI Program Office ... in Profile}

Since its founding, NASA has been dedicated to the advancement of aeronautics and space science. The NASA Scientific and Technical Information (STI) Program Office plays a key part in helping NASA maintain this important role.

The NASA STI Program Office is operated by Langley Research Center, the lead center for NASA's scientific and technical information. The NASA STI Program Office provides access to the NASA STI Database, the largest collection of aeronautical and space science STI in the world. The Program Office is also NASA's institutional mechanism for disseminating the results of its research and development activities. These results are published by NASA in the NASA STI Report Series, which includes the following report types:

- TECHNICAL PUBLICATION. Reports of completed research or a major significant phase of research that present the results of NASA programs and include extensive data or theoretical analysis. Includes compilations of significant scientific and technical data and information deemed to be of continuing reference value. NASA counter-part of peer reviewed formal professional papers, but having less stringent limitations on manuscript length and extent of graphic presentations.

- TECHNICAL MEMORANDUM. Scientific and technical findings that are preliminary or of specialized interest, e.g., quick release reports, working papers, and bibliographies that contain minimal annotation. Does not contain extensive analysis.

- CONTRACTOR REPORT. Scientific and technical findings by NASA-sponsored contractors and grantees.
- CONFERENCE PUBLICATION. Collected papers from scientific and technical conferences, symposia, seminars, or other meetings sponsored or co-sponsored by NASA.

- SPECIAL PUBLICATION. Scientific, technical, or historical information from NASA programs, projects, and missions, often concerned with subjects having substantial public interest.

- TECHNICAL TRANSLATION. Englishlanguage translations of foreign scientific and technical material pertinent to NASA's mission.

Specialized services that help round out the STI Program Office's diverse offerings include creating custom thesauri, building customized databases, organizing and publishing research results ... even providing videos.

For more information about the NASA STI Program Office, you can:

- Access the NASA STI Program Home Page at http:/ / www.sti.nasa.gov/STIhomepage.html

- E-mail your question via the Internet to help@sti.nasa.gov

- Fax your question to the NASA Access Help Desk at (301) 621-0134

- Phone the NASA Access Help Desk at (301) 621-0390

- Write to: NASA Access Help Desk NASA Center for AeroSpace Information 800 Elkridge Landing Road Linthicum Heights, MD 21090-2934 
NASA Technical Memorandum 113177

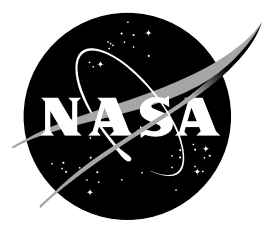

\section{Improvement in Suppression of Pulsed Nd:YAG Laser Light With Iodine Absorption Cells for Filtered Rayleigh Scattering Measurements}

Richard G. Seasholtz and Alvin E. Buggele

Lewis Research Center, Cleveland, Ohio

Prepared for the

Conference on Optical Technology in Fluid, Thermal, and Combustion Flow sponsored by the Society of Photo-Optical Instrumentation Engineers

San Diego, California, July 27-August 1, 1997

National Aeronautics and Space Administration

Lewis Research Center 
Available from

NASA Center for Aerospace Information 800 Elkridge Landing Road

Linthicum Heights, MD 21090-2934

Price Code: A03
National Technical Information Service 5287 Port Royal Road Springfield, VA 22100 Price Code: A03 


\title{
Improvement in suppression of pulsed Nd:YAG laser light with iodine absorption cells for filtered Rayleigh scattering measurements
}

\author{
Richard G. Seasholtz and Alvin E. Buggele \\ NASA Lewis Research Center \\ Cleveland, $\mathrm{OH} 44135$
}

\begin{abstract}
Filtered Rayleigh scattering using iodine absorption cells is an effective technique for obtaining density, temperature, and velocity measurements in high speed confined flows. By tuning a single frequency laser to a strong iodine absorption line, stray scattered laser light can be greatly suppressed. For example, the minimum transmission predicted by an iodine absorption model calculation is less than $10^{-5}$ at the $18788.44 \mathrm{~cm}^{-1}$ line using a $200 \mathrm{~mm}$ absorption cell containing iodine vapor at $0.46 \mathrm{~T}$. Measurements obtained by other researches using a $\mathrm{CW}$ Nd:YAG laser agree with the model calculations. However, measurements made by us and by others using Q-switched, injection-seeded, frequency doubled Nd:YAG lasers only show minimum transmission of about $3 \times 10^{-3}$. This greatly reduces the applicability of the filtered Rayleigh scattering technique using these lasers in experiments having large amounts of stray scattered laser light. The purposes of the present study are to characterize the spectrum of the excess light transmitted by the iodine cell and to make changes to the laser to reduce the transmitted laser light. Transmission data as a function of laser frequency for the iodine absorption line at $18788.44 \mathrm{~cm}^{-1}$ are presented. A planar mirror Fabry-Perot interferometer was used to characterize the frequency spectrum of the light passed through the cell. Measurements taken with the laser tuned to the center of the iodine absorption line show the light transmitted through the iodine cell to have a component with a bandwidth of about $40 \mathrm{GHz}$. This is probably caused by other modes in the laser that exist in spite of the single frequency injection beam. A second broadband component was also observed, possibly caused by the laser flash lamps or by fluorescence. An intracavity etalon was installed in the laser oscillator cavity to suppress the $40 \mathrm{GHz}$ component. Measurements taken with the etalon tuned to the injection frequency showed a reduction in the transmitted laser light. This improvement allows the iodine cell to block significantly more of the stray laser light in filtered Rayleigh scattering experiments. Examples are given of filtered Rayleigh scattering measurements showing the effect of the etalon on measurements taken in a Mach 3 flow in the NASA Lewis 4 inch by 10 inch supersonic wind tunnel.
\end{abstract}

Keywords: Rayleigh scattering, iodine absorption, Fabry-Perot interferometers, Nd:YAG lasers

\section{INTRODUCTION}

Rayleigh scattering is defined as the elastic scattering of light from particles smaller than the wavelength of the light. In particular, Rayleigh scattering from the gas molecules that constitute the flow offers the basis for a valuable diagnostic technique because the Rayleigh scattering spectrum is a function of the molecular velocity distribution. Analysis of the measured spectrum can provide gas density, temperature, and bulk velocity data. Both point and planar imaging techniques can be used. Many applications involve flows in wind tunnels or other enclosed flows where optical access is provided by windows. The passage of laser light through windows generally produces a relatively large amount of scattering. It is often difficult to exclude this stray light from the field of view of the imaging system. Since the Rayleigh scattering is typically weaker than this stray light, it is difficult to obtain the desired information from the image. This is particularly true for molecular Rayleigh scattering, which is weaker than scattering from particulates or aerosols. One technique for eliminating the stray light is to subtract it from the image. For example, if the flow chamber can be evacuated, an image can be obtained that contains only the stray scattered light. This image can then be subtracted from images containing both the stray light and the Rayleigh scattering to obtain an image of only the Rayleigh scattering. Another approach is to take images at two or more known gas densities or with two or more gases with different Rayleigh scattering cross sections; the part of the measured light due to stray scattered light can then be obtained by extrapolation. Since the stray light distribution is a function of the location of the incident beam relative to the experimental apparatus, these measurements generally need to be done at each measurement position. Also, for low light level measurements, which often are shot noise limited, subtraction of the stray light eliminates the mean value, but not the random shot noise. A better approach is to filter the scattered light to eliminate 
the stray light while retaining the Rayleigh scattering. This can be done if the wavelength of the scattered light is shifted from the wavelength of the incident light and if a sufficiently sharp cutoff or notch filter is used to block light at the laser frequency while passing the desired Rayleigh scattered light. This is the basis for the technique called filtered Rayleigh scattering.

Filtered Rayleigh scattering using a molecular iodine vapor absorption cell has been applied to a variety of flows. Some applications of filtered Rayleigh scattering use small particles entrained in the flow. These particles can be injected into the flow, or they can be formed by condensation of water vapor or some other gas such as carbon dioxide. Such condensates frequently are formed in highly expanded flows, such as supersonic jets and wind tunnels, and can be used as a fairly strong scattering medium for visualization. Examples include studies of turbulent boundary layers ${ }^{1}$, shock position determination ${ }^{2}$, and free jet studies ${ }^{3}$. Reliance on condensates, however, generally limits the measurements to velocity and to visualization of flow features; quantitative results for gas density and temperature are not obtained. In other applications, however, molecular Rayleigh scattering can be used to derive density, temperature, and velocity of pure gases or of gas mixtures with known composition $^{4,5}$.

In a previous study ${ }^{6}$, we used filtered Rayleigh scattering to measure mole fraction in a study of mixing of helium injected into supersonic crossflow. However, the results were not as good as expected. The amount of stray scattered laser light transmitted by the iodine cell was much larger than predicted by iodine absorption model calculations. This high level of extraneous background resulted in a reduction in the accuracy of the mole fraction data. For example, the uncertainty in mole fraction was increased from less than 5\% to about more than $15 \%$ for a ratio of $20: 1$ of background to Rayleigh scattering (fig. 2 of ref. 6). This discrepancy between the predicted and measured degree of suppression of laser light was the motivation for the present study.

The objectives of the present study were to characterize the spectrum of the excess light transmitted by the iodine cell and, if possible, to take measures to reduce the residual transmitted light. Transmission data as a function of laser frequency for the iodine absorption line at $18788.44 \mathrm{~cm}^{-1}$ for a Q-switched, injection-seeded Nd:YAG laser are presented. A planar mirror Fabry-Perot interferometer was used to characterize the frequency spectrum of the light passed through the cell. Measurements taken with the laser tuned to the center of the iodine absorption line show the residual light transmitted through the iodine cell to have a component with a bandwidth of about $40 \mathrm{GHz}$. This is probably caused by other modes in the laser that exists in spite of the single frequency injection beam. A second broadband component also was observed, possibly caused by the laser flash lamps or by fluorescence. An intracavity etalon was installed in the laser oscillator cavity to suppress the $40 \mathrm{GHz}$ component. Measurements taken with the etalon tuned to the injection frequency showed a reduction in residual laser light. This improvement allows the iodine cell to block much more of the stray laser light in filtered Rayleigh scattering experiments. Finally, examples of filtered Rayleigh scattering measurements showing the effect of the etalon on measurements taken in a Mach 3 flow in the NASA Lewis 4 inch by 10 inch supersonic wind tunnel are presented.

\section{FILTERED RAYLEIGH SCATTERING}

Filtered Rayleigh scattering is based on the use of atomic or molecular filters to block undesired narrowband light. Various filter media have been used for atmospheric temperature and velocity measurements including iodine vapor filters with argon-ion lasers at $514.5 \mathrm{~nm}^{7,8}$, a potassium filter with an injection-seeded pulsed alexandrite laser at $770 \mathrm{~nm}^{9}$, a CW tunable dye laser with a barium filter at $553.7 \mathrm{~nm}^{10}$, and a pulsed dye laser with a cesium filter at $388.9 \mathrm{~nm}^{11}$. The technique has been developed by Miles and his coworkers ${ }^{12}$ for high speed fluid flow measurements using frequency-doubled pulsed $\mathrm{Nd}$ :YAG lasers and iodine filters. Iodine is a useful filtering medium because its spectrum contains a number of strong absorption lines at both the $514 \mathrm{~nm}$ argon-ion and $532 \mathrm{~nm} \mathrm{Nd:YAG} \mathrm{wavelengths.} \mathrm{More} \mathrm{recent} \mathrm{work}{ }^{13}$ has been directed at using an atomic mercury line at $253.7 \mathrm{~nm}$ with a titanium:sapphire laser. Working in the ultraviolet offers the advantages of a much larger Rayleigh scattering cross section and reduced reflectivity of metallic surfaces.

In filtered Rayleigh scattering the laser must emit essentially all of its light in a narrow bandwidth (much narrower than the width of the absorption line being used). Also, the laser must be tunable, at least over a small wavelength range, so its frequency can be set to the frequency of the absorption line. Light at this frequency (which includes the stray scattered laser light) is strongly absorbed, while the portion of the Rayleigh scattered light that falls outside the absorption band is transmitted. Assuming that the laser output has all of its energy near the maximum iodine absorption, the cell parameters can be adjusted to give an almost arbitrarily large attenuation. The detector then only sees light that falls outside the absorption 
band. Other sources of light at frequencies other than the laser frequency may also exist; examples include light from the laser flashlamps and fluorescence from the windows and surfaces illuminated by the laser beam. This broadband light may need to be suppressed using narrow band interference filters.

If scattering from particulates or aerosols is used, the spectral width of the scattered light is very narrow. Broadening is only caused by flow turbulence and by Brownian motion for sufficiently small particles.

If molecular Rayleigh scattering is used, the scattering is from the gas molecules making up the flow. Since the gas molecules are moving with a range of velocities (usually given by a Maxwellian distribution) the light scattered is frequency broadened as well as shifted by the mean gas velocity. Rayleigh scattering from low density gases generally has a Gaussian spectrum, while scattering from high density gases has a triple peak spectrum due to collective effects of the gas molecules (Brillouin scattering). The spectrum of molecular Rayleigh scattering for a low density gas is

$$
S\left(f-f_{o}\right) d f=\frac{1}{\sqrt{\pi} a K} \exp \left\{-\left[\frac{2 \pi\left(f-f_{o}\right)-\mathbf{K} \cdot \mathbf{u}}{a K}\right]^{2}\right\} d f
$$

where $f_{o}$ is the laser frequency, $\mathbf{K}=\mathbf{k}_{\mathrm{s}}-\mathbf{k}_{\mathrm{o}}$ is the interaction wave vector with magnitude (wave number) $K=(4 / \lambda) \sin \left(\theta_{\mathrm{s}} / 2\right), \mathbf{k}_{\mathrm{o}}$ and $\mathbf{k}_{\mathrm{s}}$ are the wave vectors of the incident and scattered light, $\theta_{\mathrm{s}}$ is the scattering angle, $a=(2 \kappa T / \mathrm{m})^{1 / 2}$ is the most probable molecular speed (with $\kappa$ being Boltzmann's constant, $m$ the molecular mass, $T$ the gas temperature), and $\mathbf{u}$ is the mean gas velocity. Note that the spectral peak is shifted by a frequency proportional to the component of the bulk velocity in the $\mathbf{K}$ direction. (This shift, of course, is the same shift as would occur in scattering from particles imbedded in the flow.

For a sufficiently large mean velocity (at least supersonic) the molecular Rayleigh scattered light is completely shifted outside the iodine absorption band. For lower mean velocities (or even zero velocity), some the Rayleigh scattered light is within the absorption band while some falls outside. In this case, the detected light corresponds to only a fraction of the total Rayleigh scattered light and has a spectrum given by

$$
S_{\text {out }}(f)=\int S(f) I_{I 2}(f) d f
$$

where $I_{12}(f)$ is the absorption spectrum of the filter. Figure 1 shows the concept with an idealized square-shaped absorption line. Here the gas velocity is assumed to be high enough so that the Rayleigh scattered light is entirely shifted outside the absorption band. For lower velocities, the Rayleigh scattering spectrum may partially overlap the absorption line, with the consequence that the spectrum of the light emerging from the filter will be modified acccording to equation 2 .

\section{IODINE ABSPORPTION SPECTRUM}

A model developed by Forkey ${ }^{14}$ is used to calculate the absorption spectrum of iodine vapor. Figure 2 shows the absorption spectrum for the wavelength range of a frequency-doubled Nd:YAG laser. For this example, the cell length is $200 \mathrm{~mm}$, the iodine vapor pressure is $0.46 \mathrm{~T}$, and the cell temperature is $323 \mathrm{~K}$. For these iodine cell parameters, the attenuation varies from line-to-line with the line at $18788.44 \mathrm{~cm}^{-1}$ having a minimum transmission of of about $5 \times 10^{-6}$. Figure 3 shows the calculated transmission for several iodine vapor pressures. Note that the attenuation of light in an absorption line is a strong function of the iodine vapor pressure. A practically unlimited degree of attenuation is predicted for the higher vapor pressures (e.g. at a vapor pressure of $1.1 \mathrm{~T}$, the minimum transmission at $18788.44 \mathrm{~cm}^{-1}$ is less than $1 \times 10^{-8}$ ).

In particular, the iodine absorption model predicts a minimum transmission of $5 \times 10^{-6}$ at the $18788.44 \mathrm{~cm}^{-1}$ line for a $200 \mathrm{~mm}$ long absorption cell containing iodine vapor at $0.46 \mathrm{~T}$. Measurements by Forkey ${ }^{14}$ using a frequency doubled CW Nd:YAG laser agree with the model calculations. However the observed attenuation both in our work and in the work of other researchers using injection seeded, frequency doubled, Q-switched Nd:YAG lasers is much less ${ }^{14,15}$, with a minimum transmission of only about $3 \times 10^{-3}$. This greatly reduces the applicability of the filtered Rayleigh scattering technique using these lasers in experiments having large amounts of stray scattered laser light. One possible explanation is that the laser is 
lasing in one or modes in addition to the mode matched to the injection seed laser. A second possibility is that the spectral lineshape is not Gaussian.

\section{EXPERIMENT}

An experiment was conducted to determine the spectrum of the light transmitted through an iodine cell with the laser tuned to the center of the $18788.44 \mathrm{~cm}^{-1}$ absorption band. The setup is shown in figure 4 . The output beam (10 mm dia.) of a Q-switched, injection-seeded, frequency doubled Nd:YAG is directed to a diffuser. The beam pulse energy (about $500 \mathrm{~mJ}$ ) was reduced by reflection from the uncoated wedge (only one of the reflected beams was used). The diffuser was viewed with a liquid nitrogen cooled CCD camera (pixel size, $15 \mu \mathrm{m}$ square) through a planar mirror Fabry-Perot interferometer (free spectral range $=111 \mathrm{GHz}$, mirror reflectance $=90 \%)$ and an iodine absorption cell $(200 \mathrm{~mm}$ length, $70 \mathrm{~mm}$ diameter $)$. The fused silica cell has an appendage which serves as a reservoir for the iodine crystals. The temperature of the appendage was controlled with a water cooled thermoelectric element that could be used to either heat the appendage above the water temperature or cool it below the water temperature. This allowed the iodine vapor pressure to be set over a wide temperature range. The main body of the cell was heated with electrical resistance tapes and was also temperature controlled. The temperature of the cell was maintained at a higher temperature than the appendage to avoid iodine condensing on the cell walls or windows. The CCD camera lens L1 (fringe forming lens) had a focal length of $50 \mathrm{~mm}$, and the collimating lens L2 had a focal length of $85 \mathrm{~mm}$. This setup allowed us to determine the spectral characteristics of the light transmitted through the iodine cell. Two laboratory computers were used. One was used to control the CCD camera and store the images. The second was equipped with a interface card that generated an analog voltage used to control the frequency of the injection seed laser.

The Fabry-Perot interferometer (fig. 5) consists of two partially transmitting planar mirrors, which act as a multiple beam interference device. Light from a point $\left(\mathrm{x}_{\mathrm{d}}, \mathrm{y}_{\mathrm{d}}\right)$ is collimated by lens L2. After multiple reflections between the mirrors, the light is focusing by L1 (the so-called fringe forming lens) on the detector plane. The transmission function (defined as the fraction of light transmitted by Fabry-Perot for a monochromatic source with frequency $f)^{16}$ is

$$
I_{F P}(\psi)=\left[1+F \sin ^{2}\left(\frac{\psi}{2}\right)\right]^{-1}
$$

where $F=1 /\left(\sin ^{2}\left(\pi / 2 N_{\mathrm{E}}\right)\right.$ where $\mathrm{N}_{\mathrm{E}}$ is the effective finesse, and $\psi$ is the phase change (neglecting any phase change on reflection) of the light between successive reflections given by

$$
\psi\left(f, \theta_{r}\right)=\frac{4 \pi f \mu d \cos \theta_{r}}{c}
$$

with $d$ the mirror separation, $\mu$ the refractive index of the medium between the mirrors, $c$ the speed of light, and $\theta_{r}$ the angle between a particular ray and the optical axis.

The observed pattern of a single frequency source has the typical ring pattern shown in figure 7a. With the innermost fringe located on the optical axis (i.e., having zero radius), the other fringe radii are given $r_{n}=f_{L l}\left(n \lambda_{o} / d\right)^{1 / 2}$ for $n=1,2,3, \cdots$ $\cdots n$, where $f_{L 1}$ is the focal length of the fringe forming lens. Note that frequency is not linear with radius, but the frequency separations are all equal to the free spectral range $F S R=c / 2 d$. The mirror spacing for this work was set at $1.357 \mathrm{~mm}$, giving a free spectral range $F S R=111 \mathrm{GHz}$. This free spectral range was selected to be larger than the spectral feature of interest to prevent the orders from overlapping. The fringe width is determined by the finesse $\mathrm{N}_{\mathrm{E}}$ of the Fabry-Perot. If the source has a broadened frequency distribution, then the fringes are also broadened

For a monochromatic extended source with frequency $f_{o}$, the fraction of the incident light transmitted through the iodine cell and the Fabry-Perot and observed on the CCD image at radius $r$ is

$$
T(r)=I_{I 2}\left(f_{o}\right) I_{F P}\left[\psi\left(f_{o}, \theta_{r}\right)\right]
$$


where $I_{I 2}(f)$ is the transmittance of the iodine cell.

For a non-monochromatic source with spectrum $S(f)$, the light transmitted through the Fabry-Perot interferometer is given by

$$
T(r)=\int S(f) I_{F P}\left[\psi\left(f, \theta_{r}\right)\right] I_{I 2}(f) \mathrm{d} f
$$

Thus the observed fringe width is related to the source spectral width broadened by the Fabry-Perot instrument function. Note that the iodine cell absorption is independent of the angle $\theta_{r}$ (except for changes in the optical path length through the cell)

\section{EXPERIMENTAL RESULTS}

The total intensity transmitted by the iodine cell through the Fabry-Perot interferometer as a function of laser frequency is shown in figure 6 along with the transmission predicted by Forkey's model. The iodine vapor pressure was $0.46 \mathrm{~T}$ and the cell body temperature was $323 \mathrm{~K}$. The transmitted light was measured over a square region centered on the Fabry-Perot interferometer fringes and included only the central part of the image where the transmitted light was not significantly vignetted. Note that the measured transmission of the $532 \mathrm{~nm}$ light through the iodine cell is about two orders of magnitude larger than the transmission predicted by Forkey's model. Fabry-Perot interferometer images taken at various laser frequencies at the $18878.44 \mathrm{~cm}^{-1}$ iodine absorption line are shown in figure 7. If the absorption cell worked perfectly, no rings would be visible and the entire image would be black. Figure $7 \mathrm{a}$ is for the laser frequency outside the absorption line. This shows the expected sharp fringes for single frequency light. The lower part of the figure shows a horizontal trace of the image through the center of the fringe pattern. Figure $7 \mathrm{~b}$ shows an image with the laser frequency on the slope of the iodine line. Here, the laser light at the injection frequency is somewhat suppressed, but the transmitted light is still dominated by light at the injection frequency. Figure $7 \mathrm{c}$ shows the image with the laser tuned so that the light at the injection frequency is almost completely suppressed. Light not at the injection frequency is visible. Finally, figure $7 \mathrm{~d}$ shows the image with the laser tuned to the maximum absorption. This image shows that the light within the absorption band is strongly attenuated, but a significant amount of light remains at frequencies outside the absorption band. The residual light appears to have two components. One has a FWHM bandwidth (measured from figure 7d) of $40 \mathrm{GHz}$. The other component appears to broadband (with band width at least greater than the free spectral range of the Fabry-Perot interferometer). This broadband component could be due to a variety of factors such as broadband emission from the laser flashlamps or fluorescence from the iodine. Use of a narrowband interference filter can be used to reduce this broadband light, although the transmitted Rayleigh scattering will typically be reduced by $50 \%$ or more depending on the filter bandwidth.

After these measurements were made, a solid fused silica etalon was installed in the oscillator cavity of the laser. The etalon thickness was $3.0 \mathrm{~mm}$, which corresponds to a free spectral range of $35.5 \mathrm{GHz}$. The purpose of using the intracavity etalon with the injection seeded laser (which is not normally done) was to suppress the frequencies lying outside the iodine absorption line that were observed in the first measurements. The etalon tilt relative to the optical axis was adjusted with the injection seeder on to give a stable pulse with minimum Q-switch built up time delay. Images were then obtained using the same setup used for the measurements described above. For these measurements, the seed frequency was set to the minimum of the $18788.44 \mathrm{~cm}^{-1}$ iodine line. Figure 8 shows images taken at iodine vapor pressures $0.01 \mathrm{~T}\left(-10^{\circ} \mathrm{C}\right), 0.08 \mathrm{~T}\left(10^{\circ} \mathrm{C}\right)$, $0.20 \mathrm{~T}\left(20^{\circ} \mathrm{C}\right)$, and $0.46 \mathrm{~T}\left(30^{\circ} \mathrm{C}\right)$, where the cold finger temperatures are shown in parenthesis. Calibrated neutral density filters were used to reduce the intensity for the $0.01,0.08$, and $0.20 \mathrm{~T}$ images. A $10 \mathrm{~nm}$ laser line interference filter was also used to reduce broadband light. Note that for the $0.46 \mathrm{~T}$ iodine vapor pressure image shown in figure $8 \mathrm{~d}$, no fringes are visible. Comparison of this image with figure $7 \mathrm{~d}$ shows the improvement in the rejection of the $40 \mathrm{GHz}$ component of the laser light.

Finally, some examples of data taken in the Lewis 4 inch by 10 inch supersonic wind tunnel are shown in figure 9 . This was part of a study of injectors reported separately, where the laser beam was formed into a sheet that passed across the test section and was viewed obliquely ${ }^{17}$. Figure $9 \mathrm{a}$ and $9 \mathrm{~b}$ are time averages of 10 laser pulses. The etalon tended to drift out of optimum alignment, which was probably caused by temperature changes in the laser head. When this happened, the amount of stray laser light that passed through the iodine cell was greatly increased. High levels of stray light due to scattering from the multiple reflections of the laser light sheet at the tunnel windows are shown as vertical lines on the images. Figure 9a shows an image taken with the etalon out of alignment. The etalon was then adjusted and figure $9 \mathrm{~b}$ shows the effect. The 
stray light was greatly suppressed. Figures $9 \mathrm{c}$ and $9 \mathrm{~d}$ show another example, taken with single laser pulses, of the etalon out of alignment $(9 \mathrm{c})$ and in alignment $(9 \mathrm{~d})$. In operation, changes from the correct alignment can be easily monitored by observing a strong reflection such as seen in figures $9 \mathrm{a}$ and $9 \mathrm{c}$.

\section{CONCLUSIONS}

The degree of suppression of stray scattered laser light in filtered Rayleigh scattering measurements using injection seeded, Q-switched, frequency doubled Nd:YAG lasers and iodine absorption cells is limited because a small component of the laser light has a bandwidth of about $40 \mathrm{GHz}$. Because the bandwidth of this component is much greater than the width of the iodine absorption line, it is not blocked. The result is that the minimum transmission of the iodine cell is only about $3 \times 10^{-3}$, which is much greater than the minimum transmission predicted by an iodine absorption model and by measurements made with CW frequency doubled Nd:YAG lasers. Addition of an intracavity etalon to the oscillator cavity of the laser resulted in a significant reduction in the laser light transmitted through the iodine cell. Adjustment of the etalon passband to the injection seed laser frequency resulted in significant suppression of the $40 \mathrm{GHz}$ component of the laser output. This allows filtered Rayleigh scattering measurements to be made in experiments having larger amounts of stray scattered laser light. One operational difficulty was the result of the etalon not being temperature controlled. Thus any changes in the temperature of the laser head resulted in temperature tuning of the etalon. Because of this, the etalon required adjustment approximately every hour or two during operation in order to maintain single frequency operation. Placing the etalon in a temperature controlled oven should eliminate the need for frequent adjustments.

\section{ACKNOWLEGMENTS}

We would like to acknowledge the efforts of Mr. W. Trevor John and Mr. Bertram Floyd, who were responsible for

setting up and aligning the Rayleigh scattering optical system used for this work, Mr. Richard Senyitko and Mr. Salvatore Giordano, who were responsible for the wind tunnel preparation. Also, we thank Dr. Joseph Forkey for providing us with his iodine absorption code.

\section{REFERENCES}

1. J. Forkey, W. Lempert, W. Bogdonoff, R.B. Miles, and G. Russell, "Volumetric imaging of supersonic boundary layers using filtered Rayleigh scattering background suppression," AIAA paper 94-0491, 1994.

2. J. Forkey, S. Cogne, A. Smits, S. Bogdonoff, W.R. Lempert, and R.B. Miles, "Time-sequenced and spectrally filtered Rayleigh imaging of shock wave and boundary layer structure for inlet characterization," AIAA paper 93-2300, 1993.

3. G.S. Elliott, M. Samimy, and S.A. Arnette, "Molecular filter-based diagnostics in high speed flows," AIAA paper 930512.

4. J.A. Shirley and M. Winter, "Air-mass flux measurement system using Doppler-shifted filtered Rayleigh scattering," AIAA paper 93-0513.

5. G.S. Elliott and M. Samimy, "Rayleigh scattering technique for simultaneous measurements of velocity and thermodynamic properties," AIAA J. 34, pp. 2346-2352, 1996.

6. R.G. Seasholtz and A.E. Buggele, "Study of injection of helium into supersonic air flow using Rayleigh scattering," AIAA paper 97-0155, 1996.

7. G.E. Devlin, J.L. Davis, L. Chase, and S. Geschwind, "Absorption of unshifted scattered light by a molecular $\mathrm{I}_{2}$ filter in Brillouin and Raman scattering," Appl. Phys. 19, pp. 138-141, 1971.

8. K.F. Wall and R.K. Chang, "I $\mathrm{I}_{2}$-vapor notch filter with optical multichannel detection of low frequency-shift inelastic scattering from surface-enhanced Raman-scattering active electrodes," Optics Lett. 11, pp. 493-495, 1986.

9. S.H. Bloom, P.A. Searcy, K. Choi, R. Kremer, and E. Korevaar, "Helicopter plume detection by using an ultranarrowband noncoherent laser Doppler velocimeter," Optics Lett. 18, pp. 244-246, 1993.

10. H. Shimizu, S.A. Lee and C.Y. She, "High spectral resolution lidar system with atomic blocking filters for measuring atmospheric parameters," Appl. Opt. 22, pp. 1373-1381, 1983. 
11. H. Shimizu, K. Noguchi, and C.Y. She, "Atmospheric temperature measurement by a high spectral resolution lidar," Appl. Opt. 25, pp. 1460-1466, 1986.

12. R.B. Miles, J.N. Forkey, and W.R. Lempert, "Filtered Rayleigh scattering measurements in supersonic/hypersonic facilities," AIAA $17^{\text {th }}$ Aerospace Ground Testing Conference, July 6-8, 1992, Nashville, AIAA paper 92-3894, 1992.

13. J.N. Forkey, N.D. Finkelstein, W.R. Lempert, and R.B. Miles, "Control of experimental uncertainties in filtered Rayleigh scattering measurements," AIAA paper 95-0298, 1995.

14. J.N. Forkey, "Development and Demonstration of Filtered Rayleigh Scattering-A Laser Based Flow Diagnostic for Planar Measurement of Velocity, Temperature and Pressure," Ph.D. dissertation \#2067-T, Princeton University, 1996.

15. D. Hoffman, K.-U. Münch, and A. Leipertz., "Two-Dimensional Temperature Determination in Sooting Flames by Filtered Rayleigh Scattering," Opt. Lett. 21, pp. 525-527, 1996.

16. J.M. Vaughan, The Fabry Perot Interferometer, History, Theory, Practice and Applications, pp. 89-112, Adam Hilger, Bristol, 1989.

17. A.E. Buggele and R.G. Seasholtz, "Improved optical techniques for studying sonic and supersonic injection in Mach 3 flow," SPIE Conference on Optical Technology in Fluid, Thermal, and Combustion Flow III 3172, San Diego, July 27August 1, 1997. 


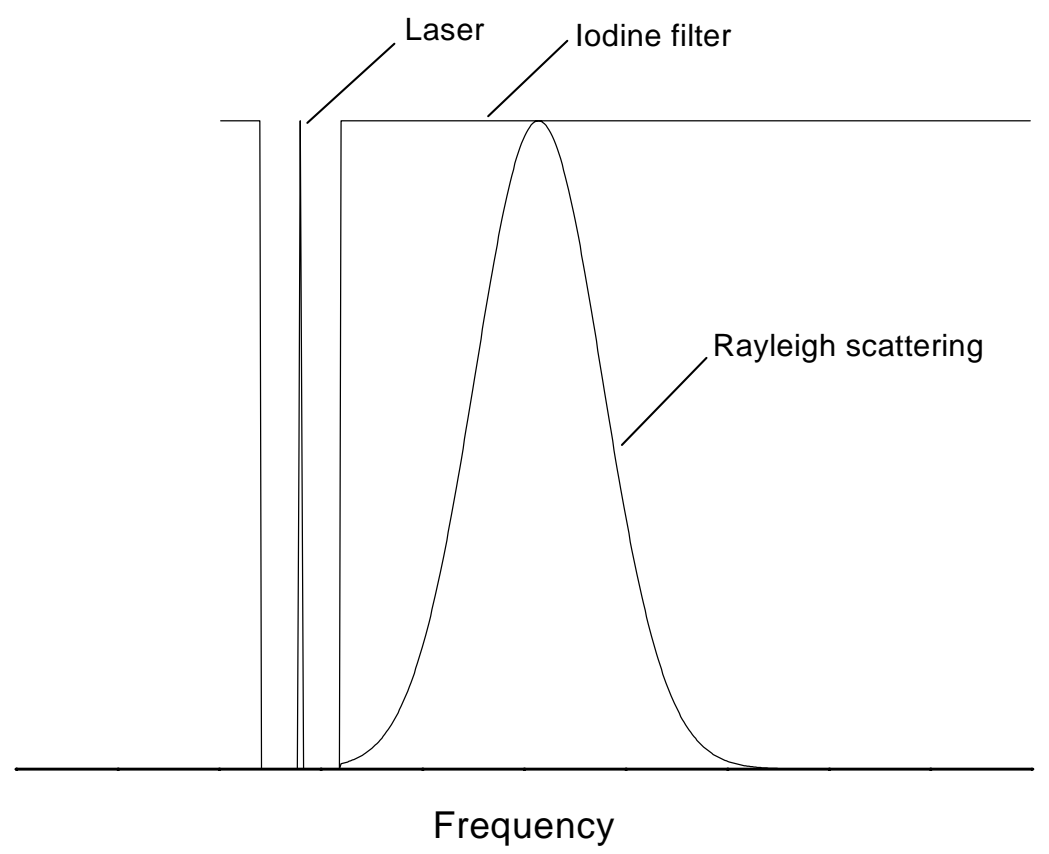

Fig. 1 - Filtered Rayleigh scattering with ideal square notch filter and Gaussian spectrum.

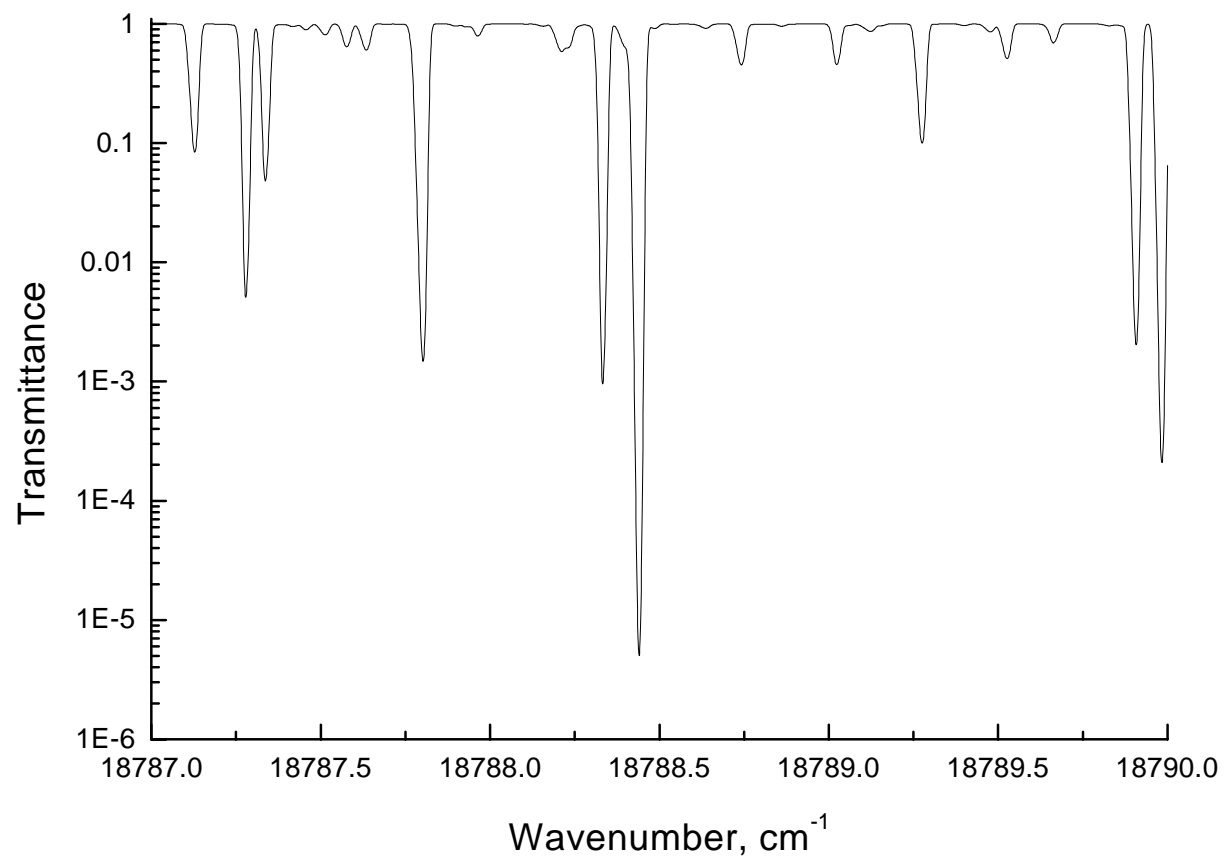

Fig. 2 - Transmittance of Iodine absorption cell calculated using Forkey's code ${ }^{14}$. Cell length is $200 \mathrm{~mm}$, iodine vapor pressure is $0.46 \mathrm{~T}$, and cell temperature is $323 \mathrm{~K}$. 


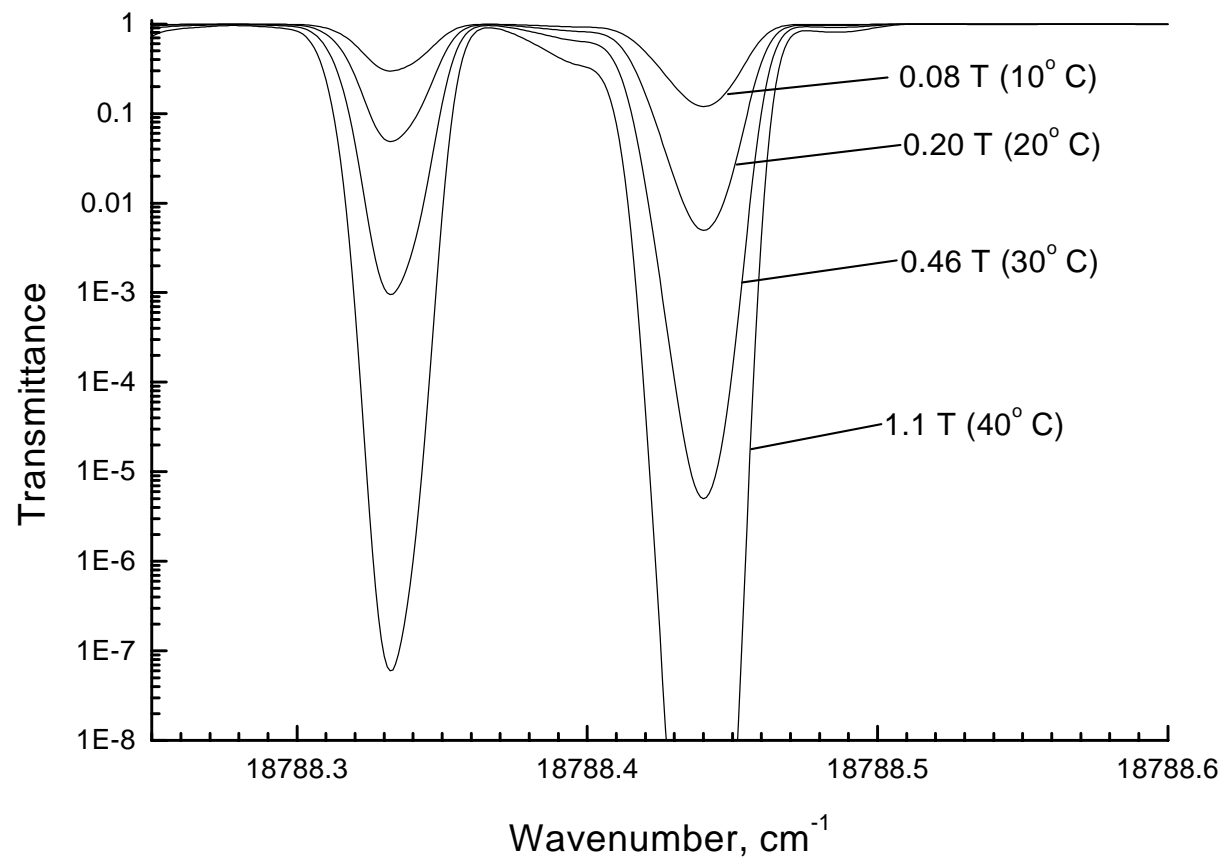

Fig. 3 - Transmittance of iodine absorption cell calculated using Forkey's code ${ }^{14}$ for four iodine vapor pressures (temperature of sidearm shown in parenthesis); Cell length $=200 \mathrm{~mm}$; Cell body temperature $=323 \mathrm{~K}$.

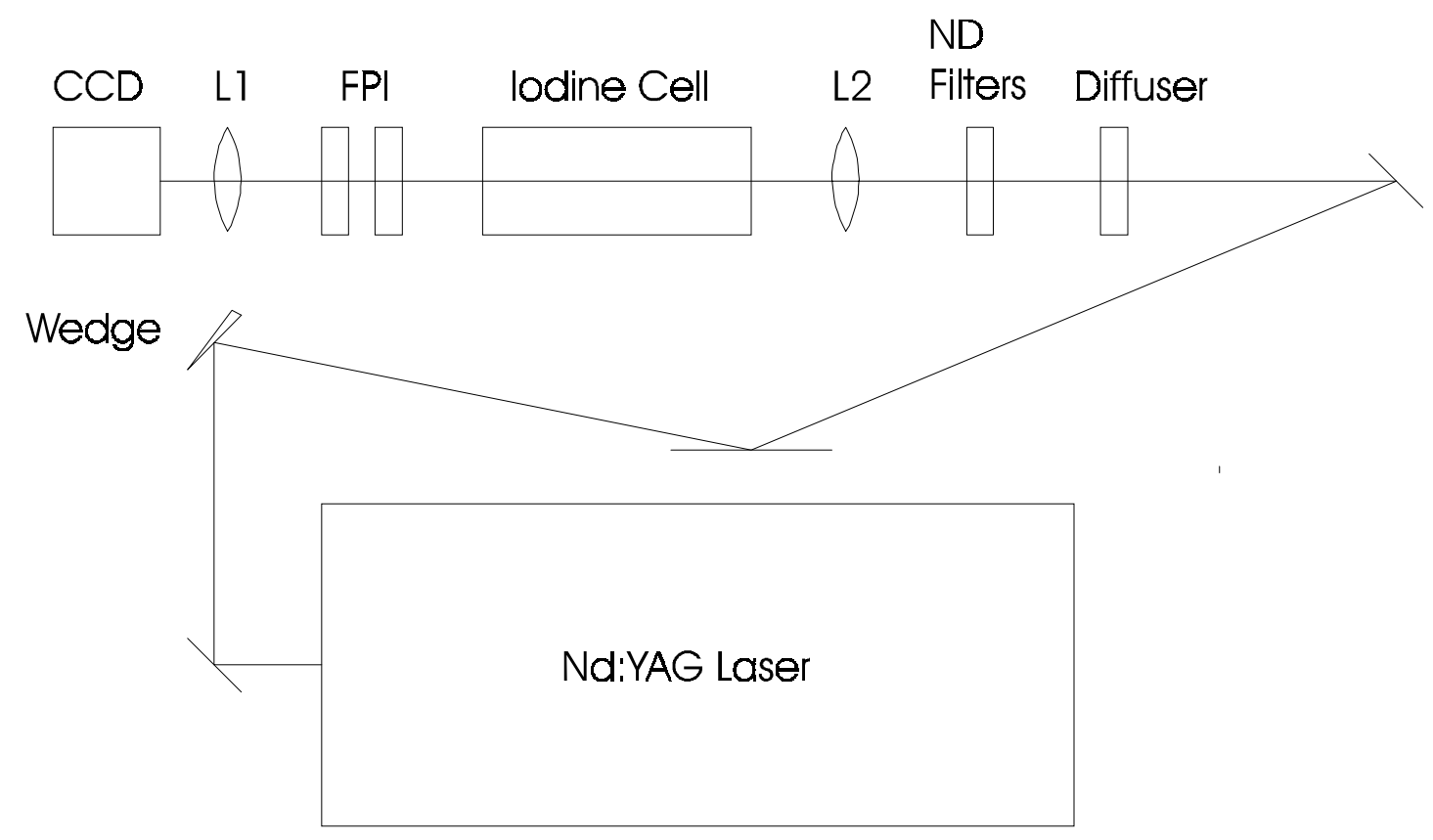

Fig. 4 - Optical layout of experiment to measure spectrum of light from Nd:YAG laser filtered by iodine absorption cell. 


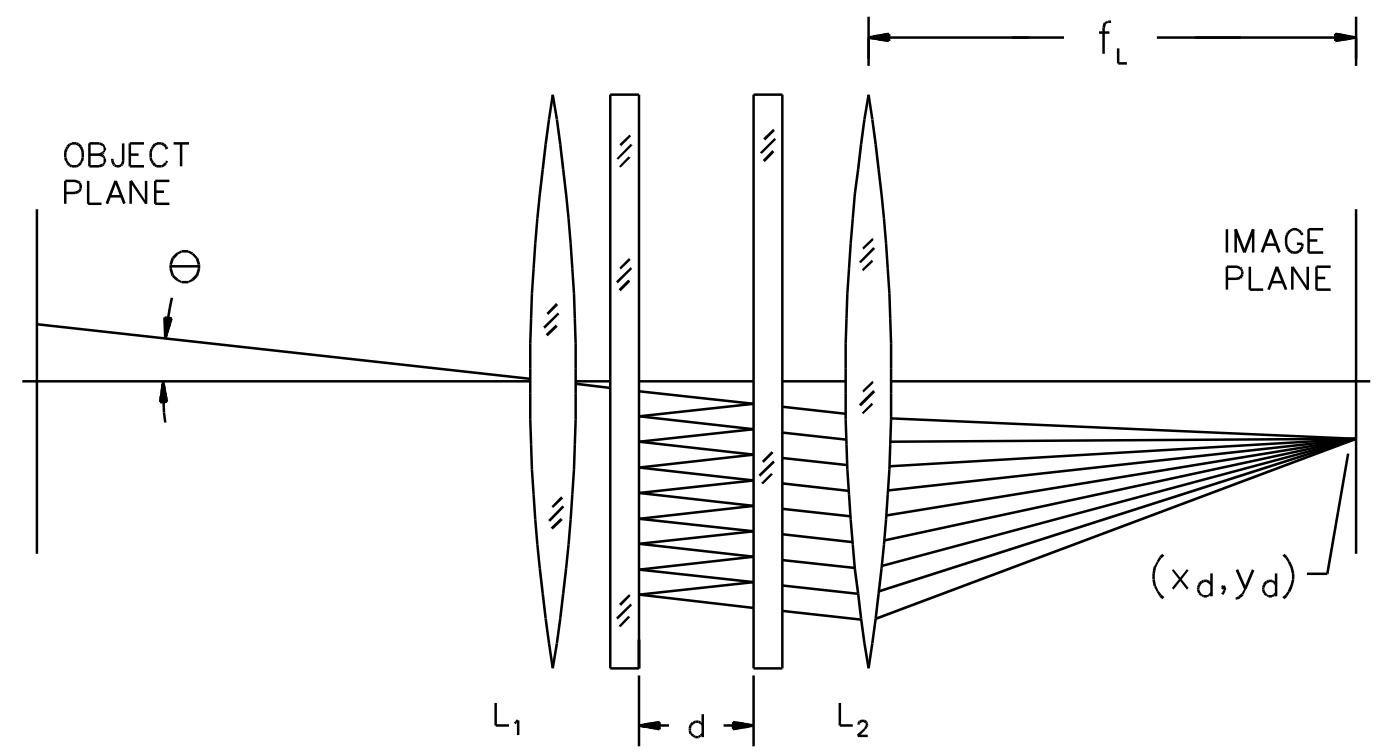

Fig. 5 - Fabry-Perot interferometer

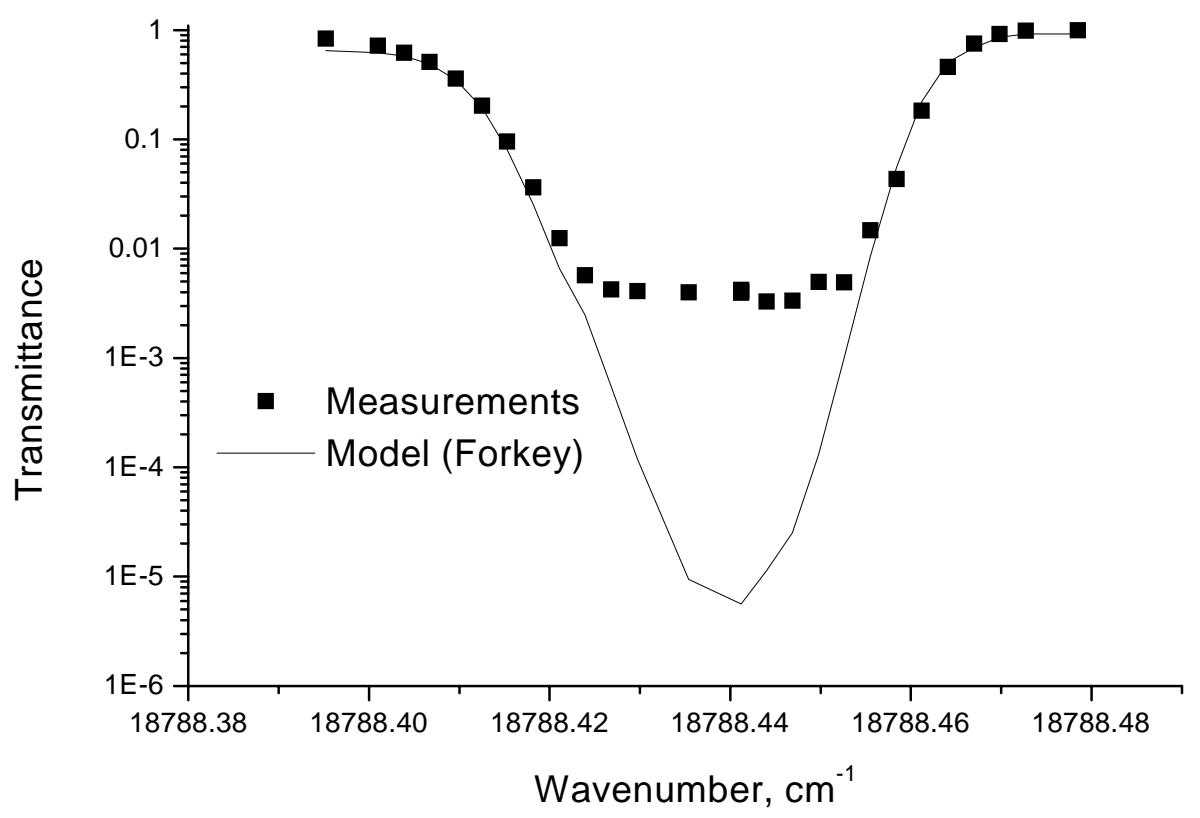

Fig. 6 - Comparison of measured transmission of Q-Switched, injection-seeded Nd:YAG laser (no intracavity etalon) and calculated spectrum using Forkey's code ${ }^{14}$. 


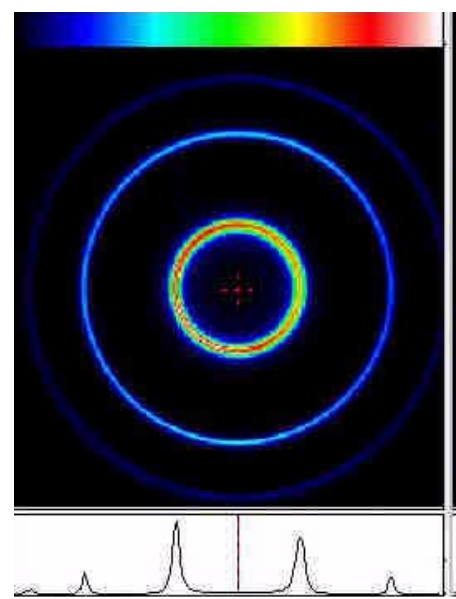

(a)

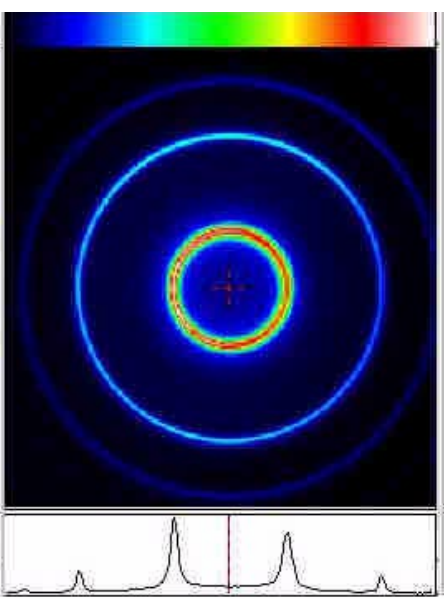

(b)

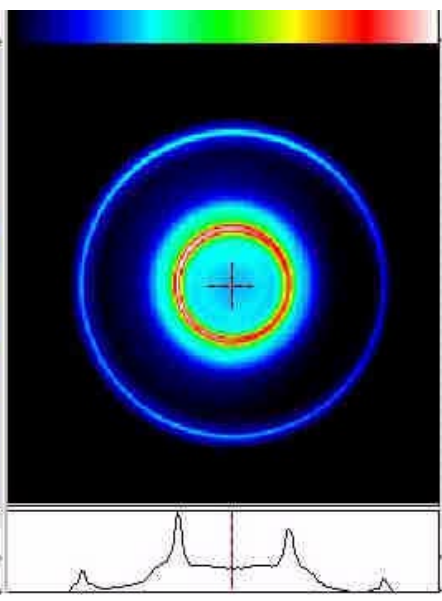

(c)

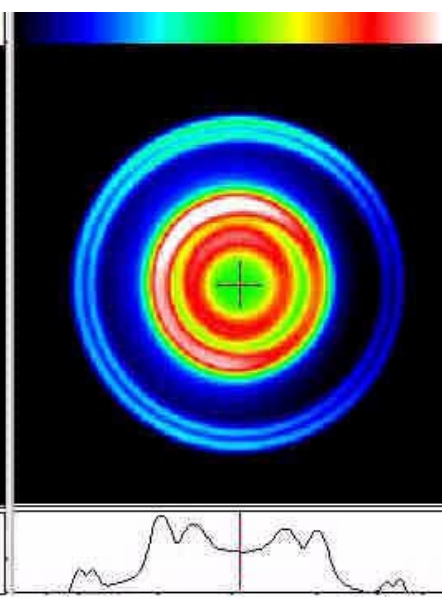

(d) laser frequencies; (a) $18788.473 \mathrm{~cm}^{-1}$, (b) $18788.456 \mathrm{~cm}^{-1}$, (c) $18788.453 \mathrm{~cm}^{-1}$, (d) $18788.441 \mathrm{~cm}^{-1}$
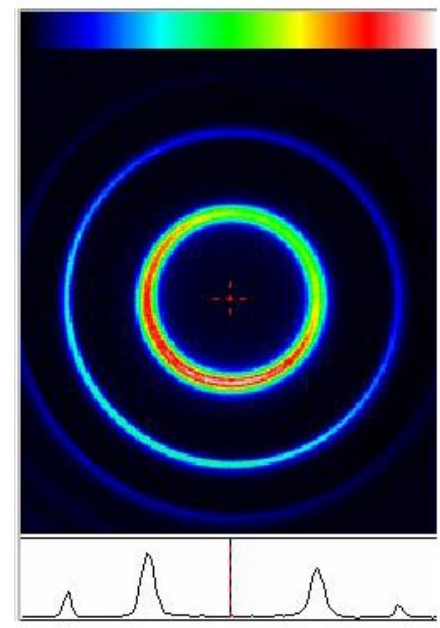

(a)
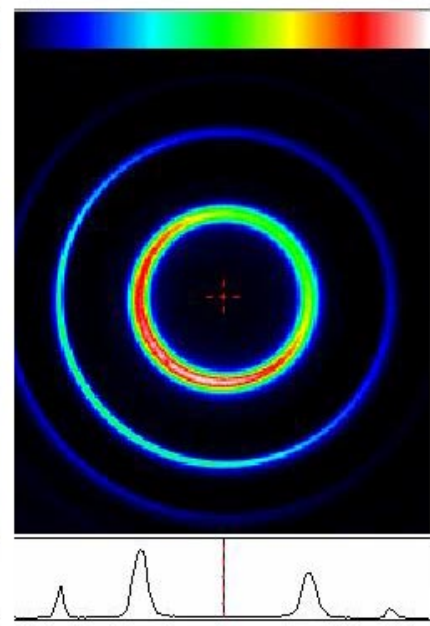

(b)

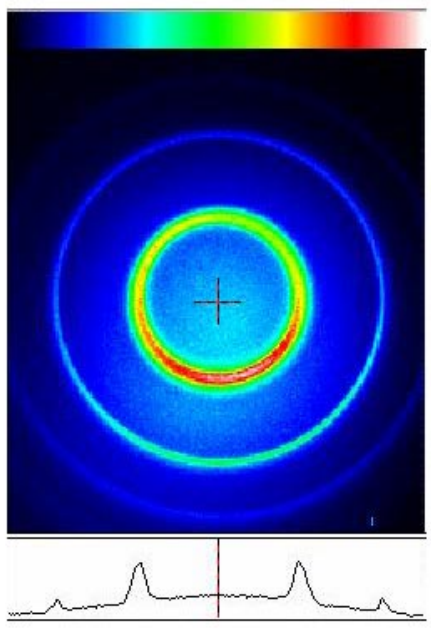

(c)

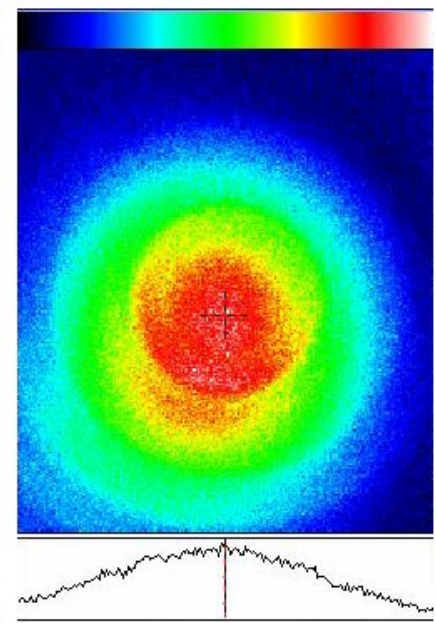

(d)

Fig. 8 - Fabry-Perot interferometer fringes for injection seeded Nd:YAG $\left(18788.44 \mathrm{~cm}^{-1}\right)$ with intracavity etalon filtered with iodine cell at different iodine vapor pressures (a) $0.01 \mathrm{~T}$, (b) $0.08 \mathrm{~T}$, (c) $0.20 \mathrm{~T}$ (d) $0.46 \mathrm{~T}$.

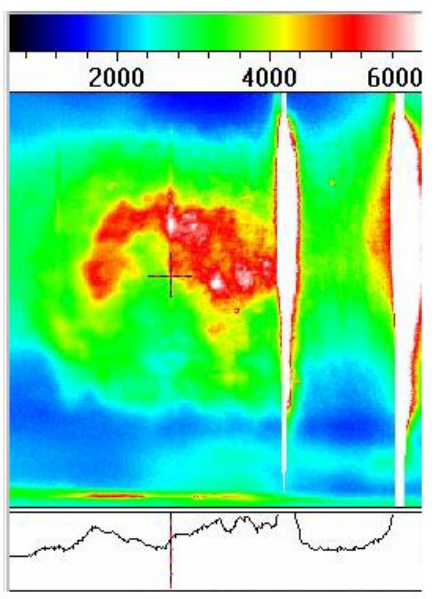

(a)

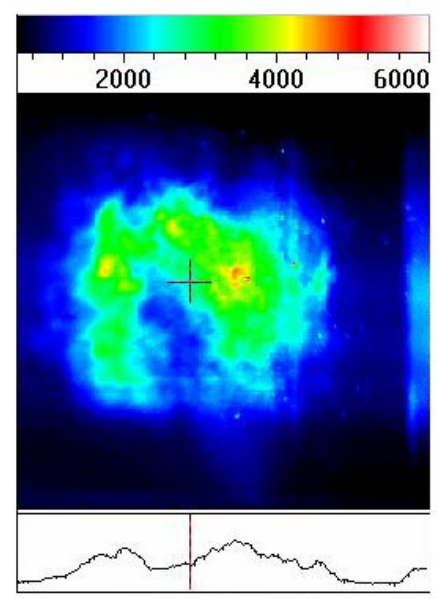

(b)

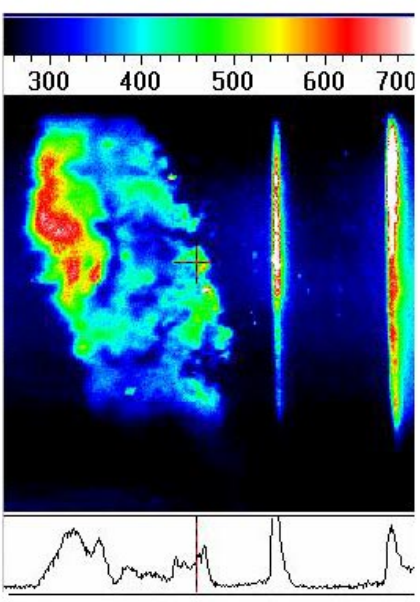

(c)

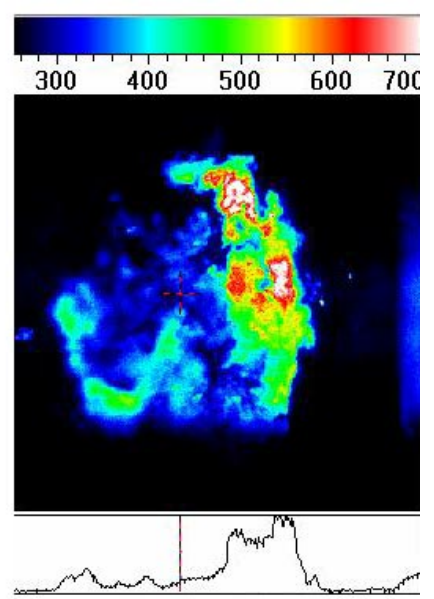

(d)

Fig. 9 - Images of condensed water vapor in air injected transversely from 0.25 inch diameter hole into Mach 3 flow (a) average, etalon not tuned (b) average, etalon tuned (c) single shot, etalon not tuned (d) single shot, etalon tuned. 
Public reporting burden for this collection of information is estimated to average 1 hour per response, including the time for reviewing instructions, searching existing data sources, gathering and maintaining the data needed, and completing and reviewing the collection of information. Send comments regarding this burden estimate or any other aspect of this collection of information, including suggestions for reducing this burden, to Washington Headquarters Services, Directorate for Information Operations and Reports, 1215 Jefferson Davis Highway, Suite 1204, Arlington, VA 22202-4302, and to the Office of Management and Budget, Paperwork Reduction Project (0704-0188), Washington, DC 20503.

\begin{tabular}{|l|l|r|}
\hline 1. AGENCY USE ONLY (Leave blank) & $\begin{array}{r}\text { 2. REPORT DATE } \\
\text { November } 1997\end{array}$ & $\begin{array}{r}\text { 3. REPORT TYPE AND DATES COVERED } \\
\text { Technical Memorandum }\end{array}$ \\
\hline
\end{tabular}

\section{TITLE AND SUBTITLE}

5. FUNDING NUMBERS

Improvement in Suppression of Pulsed Nd:YAG Laser Light With Iodine

Absorption Cells for Filtered Rayleigh Scattering Measurements

6. AUTHOR(S)

WU-519-20-53-00

Richard G. Seasholtz and Alvin E. Buggele

7. PERFORMING ORGANIZATION NAME(S) AND ADDRESS(ES)

8. PERFORMING ORGANIZATION REPORT NUMBER

National Aeronautics and Space Administration

Lewis Research Center

Cleveland, Ohio 44135-3191

E-10940

9. SPONSORING/MONITORING AGENCY NAME(S) AND ADDRESS(ES)

10. SPONSORING/MONITORING AGENCY REPORT NUMBER

National Aeronautics and Space Administration

Washington, DC 20546-0001

NASA TM-113177

11. SUPPLEMENTARY NOTES

Prepared for the Conference on Optical Technology in Fluid, Thermal, and Combustion Flow sponsored by the Society of Photo-Optical Instrumentation Engineers, San Diego, California, July 27-August 1, 1997. Responsible person, Richard G. Seasholtz, organization code 5520, (216) 433-3754.

12a. DISTRIBUTION/AVAILABILITY STATEMENT 12b. DISTRIBUTION CODE

Unclassified - Unlimited

Subject Category: 35

Distribution: Nonstandard

This publication is available from the NASA Center for AeroSpace Information, (301) 621-0390.

13. ABSTRACT (Maximum 200 words)

Filtered Rayleigh scattering using iodine absorption cells is an effective technique for obtaining density, temperature, and velocity measurements in high speed confined flows. By tuning a single frequency laser to a strong iodine absorption line, stray scattered laser light can be greatly suppressed. For example, the minimum transmission predicted by an iodine absorption model calculation is less than $10^{-5}$ at the $18788.44 \mathrm{~cm}^{-1}$ line using a $200 \mathrm{~mm}$ absorption cell containing iodine vapor at $0.46 \mathrm{~T}$. Measurements obtained by other researches using a CW Nd:YAG laser agree with the model calculations. However, measurements made by us and by others using Q-switched, injectionseeded, frequency doubled Nd:YAG lasers only show minimum transmission of about $3 \times 10^{-3}$. This greatly reduces the applicability of the filtered Rayleigh scattering technique using these lasers in experiments having large amounts of stray scattered laser light. The purposes of the present study are to characterize the spectrum of the excess light transmitted by the iodine cell and to make changes to the laser to reduce the transmitted laser light. Transmission data as a function of laser frequency for the iodine absorption line at $18788.44 \mathrm{~cm}^{-1}$ are presented. A planar mirror Fabry-Perot interferometer was used to characterize the frequency spectrum of the light passed through the cell. Measurements taken with the laser tuned to the center of the iodine absorption line show the light transmitted through the iodine cell to have a component with a bandwidth of about $40 \mathrm{GHz}$. This is probably caused by other modes in the laser that exist in spite of the single frequency injection beam. A second broadband component was also observed, possibly caused by the laser flash lamps or by fluorescence. An intracavity etalon was installed in the laser oscillator cavity to suppress the $40 \mathrm{GHz}$ component. Measurements taken with the etalon tuned to the injection frequency showed a reduction in the transmitted laser light. This improvement allows the iodine cell to block significantly more of the stray laser light in filtered Rayleigh scattering experiments. Examples are given of filtered Rayleigh scattering measurements showing the effect of the etalon on measurements taken in a Mach 3 flow in the NASA Lewis 4 inch by 10 inch supersonic wind tunnel.

\begin{tabular}{|c|c|c|c|}
\hline 14. SUBJECT TERMS & & & $\begin{array}{c}\text { 15. NUMBER OF PAGES } \\
17 \\
\end{array}$ \\
\hline \multicolumn{3}{|c|}{ Rayleigh scattering; Iodine absorption; Fabry-Perot interferometers; Nd:YAG lasers } & 16. PRICE CODE \\
\hline $\begin{array}{l}\text { 17. SECURITY CLASSIFICATION } \\
\text { OF REPORT } \\
\text { Unclassified }\end{array}$ & $\begin{array}{l}\text { 18. SECURITY CLASSIFICATION } \\
\text { OF THIS PAGE } \\
\text { Unclassified }\end{array}$ & $\begin{array}{l}\text { 19. SECURITY CLASSIFICATION } \\
\text { OF ABSTRACT } \\
\text { Unclassified }\end{array}$ & 20. LIMITATION OF ABSTRACT \\
\hline NSN 7540-01-280-5500 & & & $\begin{array}{l}\text { indard Form } 298 \text { (Rev. 2-89) } \\
\text { scribed by ANSI Std. Z39-18 }\end{array}$ \\
\hline
\end{tabular}

